\title{
Transarterial chemoembolization in patients with hepatocellular carcinoma: Predictors of survival
}

\author{
Summit Sawhney BSc ${ }^{1}$, Aldo J Montano-Loza MD², Peter Salat MD FRCPC ${ }^{1}$, Mairin McCarthy MBBCh FRCR MRCP1, \\ Norman Kneteman MD FRCPC ${ }^{3}$, Judith Meza-Junco MD ${ }^{4}$, Richard Owen MBBCh FRCR MRCP ${ }^{1}$
}

\begin{abstract}
S Sawhney, AJ Montano-Loza, P Salat, et al. Transarterial chemoembolization in patients with hepatocellular carcinoma: Predictors of survival. Can J Gastroenterol 2011;25(8):426-432.
\end{abstract}

BACKGROUND: Transarterial chemoembolization (TACE) is the mainstay of management for patients with hepatocellular carcinoma who are not suitable for curative treatments.

OBJECTIVE: To determine factors associated with mortality after the first TACE procedure.

METHODS: From January 2004 to May 2008, 60 patients underwent TACE as treatment for hepatocellular carcinoma. Clinical and biochemical parameters before TACE, and response after TACE, were evaluated with conventional classifications (WHO, Response Evaluation Criteria in Solid Tumors [RECIST], and European Association for the Study of the Liver [EASL] criteria) and with one-, two- and three-dimensional assessment.

RESULTS: Overall median survival after the first TACE procedure was $17.1 \pm 3.4$ months. According to Cox regression analysis, having an alpha-fetoprotein level of greater than $200 \mathrm{ng} / \mathrm{mL}$ (HR 2.35 [P=0.02]) and a Model for End-stage Liver Disease (MELD) score of greater than 10 (HR 4.19 [P=0.001]) were associated with higher risk of mortality; whereas reduction in tumour size measured in one dimension (HR $0.96[\mathrm{P}=0.005]$ ), two dimensions (HR $0.98[\mathrm{P}=0.004]$ ) and three dimensions (HR $0.98[\mathrm{P}=0.001]$ ) was associated with lower risk of mortality. Moreover, reduction in tumour size by $3 \%$ or more assessed in one, two or three dimensions was associated with lower risk of mortality (HR 0.48 [P=0.04]; HR 0.36 [P=0.01]; HR 0.31 [P=0.003], respectively). The three conventional classifications were not useful for predicting mortality (WHO: HR 1.07 [P=0.9]; RECIST: HR 0.94 [P=0.9]; EASL: HR 0.94 [P=0.9]).

CONCLUSIONS: Having an alpha-fetoprotein level of greater than $200 \mathrm{ng} / \mathrm{mL}$ and a MELD score of greater than 10 before undergoing TACE was associated with a greater risk of mortality. Conventional classifications of response were not useful for predicting mortality. Reduction in tumour size after the first TACE procedure was associated with better survival, primarily if patients had more than a $3 \%$ reduction in tumour size assessed by three-dimensional measurement.

Key Words: Hepatocellular carcinoma; Survival; Transarterial chemoembolization; Tumour size

$\mathrm{H}$ epatocellular carcinoma (HCC) is the fifth most common cancer 1 in the world, and the third most common cause of death (1). Prognosis in the majority of cases remains poor because of either advanced tumour staging or severe hepatic dysfunction. The best option for these patients is liver transplantation, with a five-year survival rate of up to $80 \%(2,3)$; however, for various reasons, most patients cannot receive a transplant. Surgical resection or percutaneous ablative techniques are considered to be curative treatments for HCC (4), but are only suitable for those with localized tumours or good underlying synthetic liver function. The majority of patients at

\section{La chimioembolisation transartérielle chez les patients ayant un carcinome hépatocellulaire : les prédicteurs de la survie}

HISTORIQUE : La chimioembolisation transartérielle (CETA) constitue le mode de prise en charge habituel des patients ayant un carcinome hépatocellulaire non admissibles à un traitement curatif.

OBJECTIF : Déterminer les facteurs associés à la mortalité après la première intervention de CETA.

MÉTHODOLOGIE : De janvier 2004 à mai 2008, 60 patients ont subi une CETA pour traiter un carcinome hépatocellulaire. Les chercheurs ont évalué les paramètres cliniques et biochimiques avant la CETA et la réponse après la CETA au moyen de classifications classiques (OMS, Response Evaluation Criteria in Solid Tumors [RECIST] et critères de l'European Association for the Study of the Liver [EASL]) et d'une évaluation unidimensionnelle, bidimensionnelle et tridimensionnelle.

RÉSULTATS : La survie médiane moyenne après la première intervention de CETA était de 17,1ะ3,4 mois. D'après l'analyse de régression de Cox, un taux de foetoprotéine alpha supérieur à $200 \mathrm{ng} / \mathrm{mL}$ (RR $2,35[\mathrm{P}=0,02])$ et un indice de modèle de maladie hépatique en phase terminale $(\mathrm{MMHT})$ supérieur à $10(\mathrm{RR} 4,19[\mathrm{P}=0,001])$ s'associaient à un risque de mortalité plus élevé, tandis que la réduction de la dimension de la tumeur mesurée en une dimension ( $R R$ 0,96 [P=0,005]), en deux dimensions $(\mathrm{RR} 0,98[\mathrm{P}=0,004])$ et en trois dimensions ( $R R$ $0,98[\mathrm{P}=0,001])$ s'associait à un risque de mortalité plus faible. De plus, une réduction d'au moins $3 \%$ de la dimension de la tumeur évaluée en une, deux ou trois dimensions s'associait à un plus faible risque de mortalité (RR 0,48 [P=0,04]; RR 0,36 [P=0,01]; RR 0,31 [P=0,003], respectivement). Les trois classifications classiques n'étaient pas utiles pour prédire la mortalité (OMS : RR 1,07 [P=0.9]; RECIST : RR 0,94 [P=0,9]; EASL : RR 0,94 [P=0,9]).

CONCLUSIONS : Un taux de fœetoprotéine alpha supérieur à $200 \mathrm{ng} / \mathrm{mL}$ et un indice de MMHT supérieur à 10 avant la CETA s'associait à un plus fort taux de mortalité. Les classifications classiques de réponse n'étaient pas utiles pour prédire la mortalité. La réduction de la dimension de la tumeur après la première intervention de CETA s'associait à une meilleure survie, surtout si la réduction de la dimension de la tumeur des patients était supérieure à $3 \%$, d'après une mesure tridimensionnelle.

presentation are palliative, unless they can be downstaged to a curative option or cannot be treated with current techniques.

Until quite recently, there was no level 3 evidence of survival benefit in patients with advanced HCC treated with transarterial chemoembolization (TACE), and its use was controversial in patients who were not suitable for curative therapies. Two randomized clinical trials in 2002 $(5,6)$ and a meta-analysis in 2003 (7) showed level 3 evidence of survival benefits of TACE compared with best support care.

The evaluation of response to TACE is transcendental because an objective response may become a surrogate marker for improved

\footnotetext{
${ }^{1}$ Department of Radiology and Diagnostic Imaging; ${ }^{2}$ Division of Gastroenterology 83 Hepatology; ${ }^{3}$ Department of Surgery, University of Alberta Hospital;

${ }^{4}$ Department of Medical Oncology, Cross Cancer Institute, Edmonton, Alberta

Correspondence: Dr Richard Owen, Department of Radiology and Diagnostic Imaging, Walter Mackenzie Health Sciences Centre, University of Alberta,

8440 112th Street, Edmonton, Alberta T6G 2B7. Telephone 780-407-1210, fax 780-407-8628, e-mail drrichardowen@tbwifi.ca

Received for publication June 24, 2010. Accepted January 24, 2011
} 
TABLE 1

Criteria for response assessment after transarterial chemoembolization in patients with hepatocellular carcinoma

\begin{tabular}{|c|c|c|c|}
\hline Type of tumour response & WHO criteria & RECIST & EASL criteria \\
\hline Complete & Disappearance of all target lesions & Disappearance of all target lesions & $\begin{array}{l}\text { Absence of enhanced tumour areas, reflecting complete } \\
\text { tumour necrosis }\end{array}$ \\
\hline Partial & $\geq 50 \%$ decrease & $\geq 30 \%$ decrease & $\geq 50 \%$ decrease of enhanced areas \\
\hline Stable disease & $\leq 50 \%$ decrease and $\leq 25 \%$ increase & $\leq 30 \%$ decrease and $\leq 20 \%$ increase & $\leq 50 \%$ decrease and $\leq 25 \%$ increase of enhanced areas \\
\hline Progressive disease & $\geq 25 \%$ increase or new lesions & $\geq 20 \%$ increase or new lesions & $\begin{array}{l}\geq 25 \% \text { increase of enhanced lesions or new enhanced } \\
\text { lesions }\end{array}$ \\
\hline
\end{tabular}

EASL European Association for the Study of the Liver; RECIST Response Evaluation Criteria in Solid Tumors

survival. Criteria have been developed for response assessment, including WHO $(8,9)$, the Response Evaluation Criteria in Solid Tumors (RECIST) $(10,11)$ and the European Association for the Study of the Liver (EASL) criteria (12) (Table 1). However, these criteria have limitations; for example, WHO and RECIST evaluate only bidimensional and unidimensional tumour measurements, and disregard the extent of necrosis, whereas the EASL criteria evaluate response by measuring the extent of tumour necrosis; however, there are a lack of data supporting correlations with improving survival.

In the present retrospective analysis of prospectively acquired data, we analyzed factors associated with mortality after the first TACE procedure. We also determined the value of conventional classifications (ie, WHO, RECIST and EASL) to measure response and predict survival after TACE, and analyzed the clinical utility of the new values of response, using one-, two- and three-dimensional tumour measurements expressed as percentages to predict outcome.

\section{METHODS}

\section{Study population}

Between January 2004 and May 2008, 60 consecutive patients with HCC underwent TACE at the University of Alberta Hospital (Edmonton, Alberta). HCC was diagnosed using characteristic noninvasive imaging criteria (computerized axial tomography [CAT] scan or magnetic resonance imaging [MRI]) in 37 patients, and with liver biopsy in 23 patients. Each patient was followed after the first TACE procedure until specific end points were reached, which included death, liver transplant, resection or treatment failure (development of metastasic disease post-TACE and/or deterioration in liver function post-TACE). The present study was approved by the local ethics committee.

\section{Chemoembolization criteria}

Inclusion criteria: Preprocedure requirements: assumed to not be a candidate for 'curative treatment' (surgery or radiofrequency ablation, percutaneous ethanol injection) due to location, size, etc. Biopsyproven or noninvasive criteria for HCC, preprocedure dynamic crosssectional imaging (CAT scan or MRI), and tumours greater than $2 \mathrm{~cm}$ in diameter, bilirubin level lower than $50 \mu \mathrm{mol} / \mathrm{L}$, Model for End-stage Liver Disease (MELD) score of less than 30, Child-Pugh class A or B, and Eastern Cooperative Oncology Group (ECOG) score of 0 to 1.

Exclusion criteria: Very advanced disease (multifocal tumour, large mass greater than $8 \mathrm{~cm}$ in diameter, etc), more than $50 \%$ liver volume, portal vein invasion, metastasis, ECOG score of greater than 1, life expectancy of less than three months, severe liver disease with MELD score of greater than 30, encephalopathy, or multigated aquisition (MUGA) scan ejection fraction of less than $60 \%$.

\section{Chemoembolization protocol}

A MUGA scan was performed before the initial chemoembolization, after the fourth course of TACE, and after six or more courses of TACE to evaluate heart function. In patients with significant cardiac dysfunction, mitomycin or a combination of doxorubicin and mitomycin was used instead of doxorubicin alone. A triphasic abdominal CAT scan (liver mass protocol) was also performed before each first TACE, and subsequently after every second treatment to assess tumour response. Prophylactic antibiotics were given to all patients: cefazolin $1 \mathrm{~g}$ intravenously (IV) every $8 \mathrm{~h}$ (three doses) and metronidazole $500 \mathrm{mg}$ IV every $6 \mathrm{~h}$ (four doses). All patients also received diphenhydramine $50 \mathrm{mg}$ IV, ondansetron $8 \mathrm{mg} I V$ every $8 \mathrm{~h}$ (three doses) and dexamethasone $8 \mathrm{mg}$ IV every $8 \mathrm{~h}$ (three doses). Fentanyl $50 \mu \mathrm{g}$ to $150 \mu \mathrm{g}$ IV or morphine $5 \mathrm{mg}$ to $10 \mathrm{mg} \mathrm{IV}$, and midazolam $1 \mathrm{mg}$ to $5 \mathrm{mg}$ IV were used to achieve moderate sedation.

A $5 \mathrm{Fr}$ sheath was placed in the common femoral artery with selective catheterization of the superior mesenteric (SMA) and celiac axis arteries. An angiogram of the SMA was performed with delayed portal vein imaging. Further angiography of the celiac axis was performed to characterize the hepatic arterial supply. Following the initial arterial assessment, the catheter was advanced into the lobar or segmental hepatic artery supplying the tumour. If the initial $4 \mathrm{Fr}$ or $5 \mathrm{Fr}$ diagnostic catheter could be advanced into the optimal position, it was used for the TACE infusion and, in cases in which more selective catheterization was required, a 2.3 Fr or 2.5 Fr microcatheter was used (Rapid Transit, Cordis Endovascular Systems, USA, or Mira-Flex, Cook Medical, USA). In general, the TACE infusion point was chosen to enable selective tumour embolization. However, if there were separate arterial feeders, or a discrete blood supply could not be identified, a right or left hepatic arterial infusion was performed. If concern regarding hepatic synthetic function was present, a selective approach was chosen. Once the lesion and its blood supply were identified, an emulsion consisting of doxorubicin $(50 \mathrm{mg}$ in $10 \mathrm{~mL}$ of normal saline) and lipiodol (5 mL to $10 \mathrm{~mL}$ ) was injected under fluoroscopic guidance into the arterial supply of the tumour. If the bilirubin level was elevated by more than $35 \mu \mathrm{mol} / \mathrm{L}$, less than $10 \mathrm{~mL}$ of lipiodol was used. If there was continuing arterial supply to the tumour after administration of the lipiodol/doxorubicin emulsion, embolization of the feeding vessel to near stasis was achieved using polyvinyl alcohol particles $350 \mu \mathrm{m}$ to $500 \mu \mathrm{m}$ in size (Boston Scientific, USA).

Following TACE, pain medication was given as needed to maintain pain control. Second and subsequent treatments were scheduled at six-week intervals for the first four treatments, and at three-month intervals (up to a maximum of eight courses) for subsequent treatments. End points for treatment were as follows: contraindications to further TACE (deteriorating cardiac function, deteriorating hepatic function); progression of disease despite treatment; tumour regression or stabilization after a minimum of two treatments; development of metastasis; surgical resection; transplantation; or death. MUGA scans were repeated after the second, fourth, sixth and subsequent TACE procedures. Contraindications to TACE were the following: advanced liver disease (bilirubin level of greater than $50 \mu \mathrm{mol} / \mathrm{L}$, super selective embolization only in cases for which the bilirubin level was greater than $30 \mu \mathrm{mol} / \mathrm{L}$ ); Child-Pugh class C, MELD score of less than 30 and/or development of encephalopathy; renal failure (serum creatinine level of greater than $250 \mu \mathrm{mol} / \mathrm{L}$ ); coagulation abnormality (international normalized ratio of greater than 1.5; platelet levels lower than $50 \times 10^{9} / \mathrm{L}$ ); and evidence of extrahepatic spread of disease. Three qualified interventional radiologists performed the TACE procedures, with the majority completed by two interventional radiologists (28 and 30 cases each). On average, each patient underwent 2.5 TACE treatments (range one to eight). 


\section{TABLE 2}

Clinical and laboratory features at accession in patients undergoing transarterial chemoembolization $(n=60)$

\begin{tabular}{|c|c|c|}
\hline Clinical/biochemical & $\begin{array}{c}\text { Mean } \pm \text { SEM } \\
\text { or } \mathbf{n}\end{array}$ & $\begin{array}{c}\text { Range or } \\
\text { percentage }\end{array}$ \\
\hline \multicolumn{3}{|l|}{ Features at presentation } \\
\hline Age, years & $60 \pm 2$ & 24-91 \\
\hline Male:female ratio & $50: 10$ & $82: 18$ \\
\hline \multicolumn{3}{|l|}{ Etiology of cirrhosis } \\
\hline Alcohol & 11 & 18 \\
\hline $\mathrm{HCV}$ & 11 & 18 \\
\hline Alcohol + HCV & 9 & 15 \\
\hline HBV & 13 & 22 \\
\hline Cryptogenic & 11 & 18 \\
\hline Others* & 5 & 8 \\
\hline Child-Pugh class, A/B & $39 / 21$ & $65 / 35$ \\
\hline MELD score, points & $9 \pm 0.4$ & $4-17$ \\
\hline$B C L C(A / B / C)$ & $10 / 46 / 4$ & $17 / 77 / 6$ \\
\hline ALT (normal <50 U/L) & $89 \pm 9$ & 19-365 \\
\hline AST (normal <38 U/L) & $94 \pm 9$ & $11-292$ \\
\hline AP (normal 30-130 U/L) & $158 \pm 18$ & $45-846$ \\
\hline Bilirubin $(<20 \mu \mathrm{mol} / \mathrm{L})$ & $23 \pm 2$ & 8-105 \\
\hline International normalized ratio & $1.2 \pm 0.5$ & $0.9-3.0$ \\
\hline Albumin (normal 35-50 g/L) & $36 \pm 1$ & $16-50$ \\
\hline Creatinine (normal <125 $\mu \mathrm{mol} / \mathrm{L}$ ) & $83 \pm 3$ & $33-165$ \\
\hline AFP (normal <10 ng/mL) & $2664 \pm 1825$ & $1-103,225$ \\
\hline AFP $>400$ ng/mL & 16 & 27 \\
\hline Total tumour size (1D), cm & $6.9 \pm 0.6$ & $1.3-20.4$ \\
\hline Total tumour size (2D), $\mathrm{cm}^{2}$ & $51.5 \pm 8.5$ & $1.4-318.2$ \\
\hline Total tumour size (3D), $\mathrm{cm}^{3}$ & $293.9 \pm 71.8$ & $1-3053.6$ \\
\hline Tumours, n & $2 \pm 0.2$ & $1-10$ \\
\hline
\end{tabular}

${ }^{*}$ Cryptogenic primary biliary cirrhosis. 1D One dimension; 2D Two dimensions; 3D Three dimensions; AFP Alpha-fetoprotein; ALT Alanine aminotransferase; AP Alkaline phosphatase; AST Aspartate aminotransferase; BCLC Barcelona Clinic Liver Cancer staging classification; HBV Hepatitis B virus; HCV Hepatitis C virus; MELD Model for End-stage Liver Disease

\section{Assessment of response following TACE}

Tumour response was evaluated one to three months after the first TACE procedure. The evaluation of tumour response with conventional classifications, such as WHO, RECIST and EASL, was determined in 53 of 60 patients who underwent a CAT scan after the first TACE, and they were classified as complete response, partial response, stable disease or progressive disease. Then, the differences in the tumour size between the pre-TACE and post-TACE CAT scan were measured, assessed in one, two and three dimensions, with the differences expressed as a percentage. The three-dimensional assessment was performed as a surrogate of the total tumour volume, and was calculated as the sum of the volumes of all tumours $\left([4 / 3] \pi r^{3}\right.$, where $r$ is the maximum radius of each $\mathrm{HCC}$ ), as described elsewhere (13). All of the imaging studies were evaluated by only one radiologist (RO).

\section{Statistical analyses}

Fisher's exact probability test was used to compare categorical variables, while the unpaired $t$ test was used to compare differences in the means of continuous variables. Nonparametric variables in independent samples were compared using the Mann-Whitney U test. Survival was calculated using the Kaplan-Meier method, and they were compared using the log-rank (Mantel-Cox) test (14). Patients were followed after the first TACE procedure and were censored at the time of death, liver transplantation, surgical resection or at the time of their most recent visit. Prognostic factors for mortality were analyzed by Cox uni- and multivariate analysis (15). A ROC curve was plotted to measure how the response, via one-dimensional, two-dimensional and

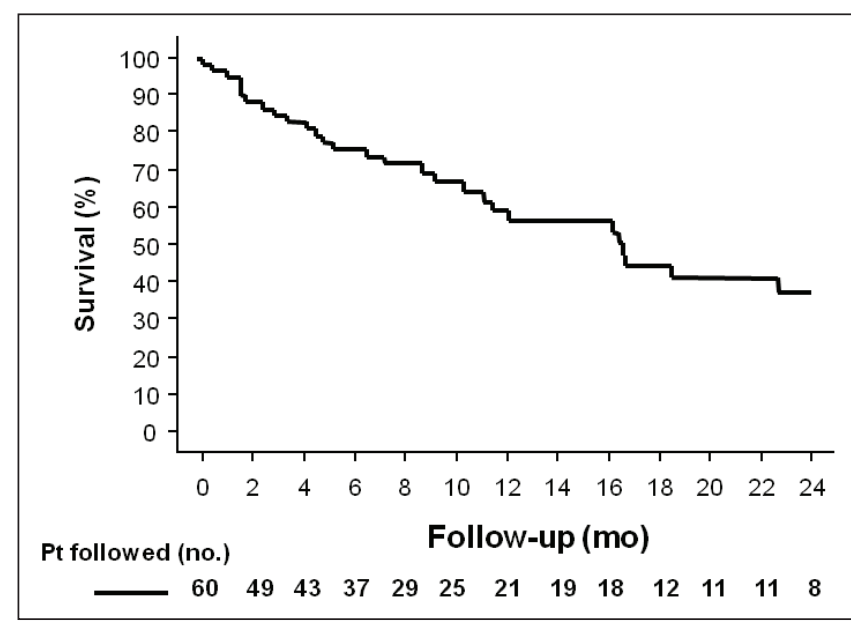

Figure 1) Overall probability of survival after the first transarterial chemoembolization procedure in patients $(\mathrm{Pt})$ with hepatocellular carcinoma. The six-month and one-year probability of survival was $74 \%$ and $60 \%$, respectively. mo Months; no Number

three-dimensional measurements after TACE (expressed as percentages) was able to discriminate mortality in patients with HCC. The validity of the model was measured by the area under the ROC curve (AUC) (16). Furthermore, ROC curves were used to determine the one-, two- and three-dimensional measurements expressed as percentage values that discriminated best between patients who died during follow-up after TACE and those who survived. Data are presented as the mean \pm SEM in the tables and text.

\section{RESULTS}

Features at accession in patients receiving TACE

The mean age of the study population was $60 \pm 2$ years (range 24 to 91 years); 50 patients ( $83 \%$ ) were men. Table 2 summarizes the cohort characteristics. All patients were cirrhotic, the majority of which were secondary to a combination of chronic active hepatitis $\mathrm{C}$ and alcohol abuse $(n=31[52 \%])$. Liver function was preserved in the majority: 39 patients $(65 \%)$ were Child-Pugh class A, and mean MELD score before TACE was $9 \pm 0.4$ points. According to the Barcelona Clinic Liver Cancer (BCLC) staging classification, 10 patients were in stage A (17\%), 46 were in stage B (77\%) and four were in stage C (6\%). The basal size of the tumour, measured in one, two and three dimensions, and the number of tumours are shown in Table 2.

Survival after the first TACE procedure in patients with HCC After the first TACE procedure, during a mean follow-up of $11 \pm 1$ months (median eight months, range one to 38 months), 31 patients died, 14 patients received a liver transplant, 11 patients were alive, three patients were lost during follow-up and one patient underwent surgical resection. The overall median survival time after first TACE was $17.1 \pm 3.4$ months (95\% CI 10.5 to 23.7 ); the probability of survival at six months was $74 \%$, and at one year was $60 \%$ (Figure 1).

Pre-TACE features associated with mortality according to univariate and multivariate Cox analysis

According to univariate Cox regression analysis of the pre-TACE variables, the alpha-fetoprotein (AFP) level (HR 1.01 [95\% CI 1.00 to 1.02]; $\mathrm{P}=0.03$ ), an AFP level of greater than $200 \mathrm{ng} / \mathrm{mL}$ (HR 2.35 [95\% CI 1.14 to 4.87]; $\mathrm{P}=0.02$ ) and a MELD score of greater than 10 (HR 4.19 [95\% CI 1.79 to 9.78]; P=0.001) were significantly associated with a higher risk of mortality (Table 3). No other significant association was found with clinical and laboratory features before TACE and the risk of mortality, including age, sex, hepatitis viral infection, and the number and size of the tumour (Table 3). 
TABLE 3

Pretransarterial chemoembolization features associated with mortality according to Cox regression analysis in patients with hepatocellular carcinoma

\begin{tabular}{|c|c|c|c|c|c|}
\hline & Mortality $(n=31)$ & Alive $(n=29)$ & HR & $95 \% \mathrm{Cl}$ & $\mathbf{P}$ \\
\hline \multicolumn{6}{|l|}{ Features associated in the univariate analysis } \\
\hline Age at diagnosis, years & $61 \pm 2$ & $58 \pm 2$ & 0.41 & $0.98-1.04$ & 0.4 \\
\hline Men:women, n:n & $26: 5$ & $24: 5$ & 1.26 & $0.48-3.29$ & 0.6 \\
\hline Viral hepatitis (B and C), n (\%) & $13(42)$ & $20(69)$ & 0.33 & $0.34-1.44$ & 0.3 \\
\hline Alanine aminotransferase (normal <50 U/L) & $80 \pm 14$ & $79 \pm 11$ & 0.99 & $0.99-1.003$ & 0.4 \\
\hline Aspartate aminotransferase (normal <38 U/L) & $95 \pm 14$ & $93 \pm 12$ & 1.00 & $0.99-1.006$ & 0.9 \\
\hline Alkaline phosphatase (normal 30-130 U/L) & $150 \pm 14$ & $143 \pm 24$ & 1.002 & 0.99-1.006 & 0.5 \\
\hline Bilirubin (normal $<20 \mu \mathrm{mol} / \mathrm{L}$ ) & $23 \pm 3$ & $24 \pm 3$ & 1.02 & $0.99-1.05$ & 0.1 \\
\hline International normalized ratio (normal 0.8-1.2) & $1.2 \pm 0.02$ & $1.2 \pm 0.08$ & 0.58 & $0.17-1.93$ & 0.4 \\
\hline Albumin (normal 35-50 g/L) & $37 \pm 1$ & $35 \pm 1$ & 0.98 & $0.92-1.04$ & 0.5 \\
\hline Creatinine (normal <125 mol/L) & $89 \pm 5$ & $76 \pm 3$ & 1.01 & $0.99-1.03$ & 0.08 \\
\hline Alpha-fetoprotein (normal <10 ng/mL) & $3891 \pm 3315$ & $925 \pm 626$ & 1.01 & $1.00-1.02$ & 0.03 \\
\hline Alpha fetoprotein >200 ng/mL & $14(45)$ & $5(17)$ & 2.35 & $1.14-4.87$ & 0.02 \\
\hline Model for End-stage Liver Disease score & $8.9 \pm 0.6$ & $8.2 \pm 0.6$ & 1.11 & $0.98-1.26$ & 0.09 \\
\hline Model for End-stage Liver Disease score >10, n (\%) & $10(32)$ & $5(17)$ & 4.19 & $1.79-9.78$ & 0.001 \\
\hline Child-Turcotte-Pugh class, A:B, n & 19:12 & $20: 9$ & 0.69 & $0.34-1.44$ & 0.3 \\
\hline BCLC, A:B:C, n & $2: 26: 3$ & 8:20:1 & 2.58 & $0.95-7.03$ & 0.06 \\
\hline Tumours, $\mathrm{n}$ & $2.0 \pm 0.3$ & $2.2 \pm 0.4$ & 1.04 & $0.83-1.31$ & 0.7 \\
\hline Total tumour size (1D), cm & $7.9 \pm 0.9$ & $5.6 \pm 0.7$ & 1.07 & $0.98-1.16$ & 0.1 \\
\hline Total tumour size (2D), $\mathrm{cm}^{2}$ & $63 \pm 13$ & $38 \pm 10$ & 1.005 & $0.99-1.011$ & 0.08 \\
\hline Total tumour size (3D), $\mathrm{cm}^{3}$ & $381 \pm 115$ & $194 \pm 76$ & 1.001 & $1.00-1.001$ & 0.06 \\
\hline \multicolumn{6}{|l|}{ Features associated in the multivariate analysis } \\
\hline Alpha-fetoprotein (normal <10 ng/mL) & $3891 \pm 3315$ & $925 \pm 626$ & 1.01 & $1.00-1.02$ & 0.008 \\
\hline Model for End-stage Liver Disease score >10, n (\%) & $10(32)$ & $5(17)$ & 4.55 & $1.92-10.78$ & 0.001 \\
\hline
\end{tabular}

Data presented as mean \pm SEM unless otherwise indicated. 1D One dimension; 2D Two dimensions; 3D Three dimensions; BCLC Barcelona Clinic Liver Cancer staging classification

In the multivariate Cox analysis, only the AFP level (HR 1.01 [95\% CI 1.00 to 1.02 ]; $\mathrm{P}=0.008)$ and a MELD score of greater than 10 (HR 4.55 [95\% CI 1.92 to 10.78]; $\mathrm{P}=0.001$ ) were independently associated with a higher risk of mortality (Table 3 ).

Evaluation of tumour response after TACE

For the analysis of tumour response after the first TACE, seven patients were excluded because they did not undergo a subsequent CAT scan after TACE (three patients transplanted post-TACE [transplantation mean $101 \pm 41$ days following TACE; median 100 days; range 31 to 173 days]; three died from treatment complications [mean $37 \pm 10$ days following TACE; median 37 days; range 19 to 54 days]; and one patient was lost during follow-up).

Using the three conventional assessments of tumour response, none of the patients achieved a complete response classification (WHO, RECIST and EASL), and most patients exhibited stable disease (Table 4). According to WHO criteria, six patients achieved partial response, 45 stable disease and two progressive disease. According to the RECIST criteria, eight patients achieved partial response, 41 stable disease and four progressive disease. According to the EASL criteria, eight patients achieved partial response, 43 stable disease and two progressive disease (Table 4).

Performance of one-, two- and three-dimensional measurements of response after TACE

The best parameters to discriminate mortality in patients with HCC after TACE were the two- and three-dimensional reduction measurements in percentage (difference between pre-TACE CAT scan and post-TACE CAT scan), with an AUC of 0.69 (95\% CI 0.54 to 0.84; $\mathrm{P}=0.02)$ for two-dimensional measurement, and an AUC of $0.72(95 \%$ CI 0.58 to $0.86 ; \mathrm{P}=0.009$ ) for three-dimensional measurement (Figure 2). The one-dimensional response was less accurate for mortality discrimination (AUC 0.65 [95\% CI 0.50 to 0.81]; $\mathrm{P}=0.07$ ) (Figure 2). The best
TABLE 4

Tumour response assessment after transarterial chemoembolization in patients with hepatocellular carcinoma

\begin{tabular}{lccc}
\hline Type of tumour & \multicolumn{3}{c}{ Criteria } \\
\cline { 2 - 4 } response & WHO & RECIST & EASL \\
\hline Complete & $0(0)$ & $0(0)$ & $0(0)$ \\
Partial & $8(15)$ & $6(11)$ & $8(15)$ \\
Stable disease & $41(77)$ & $45(85)$ & $43(81)$ \\
Progressive disease & $4(8)$ & $2(4)$ & $2(4)$ \\
\hline
\end{tabular}

Data presented as $n$ (\%). EASL European Association for the Study of the Liver; RECIST Response Evaluation Criteria in Solid Tumors

cut-off value for one-, two- and three-dimensional assessment for discrimination of mortality after TACE was a reduction of $3 \%$ or more.

Post-TACE features associated with mortality according to univariate and multivariate Cox analysis

According to univariate Cox analysis of the post-TACE variables, reduction in the tumour size measured in one dimension (HR 0.96 [95\% CI 0.93 to 0.99]; $\mathrm{P}=0.005$ ), two dimensions (HR 0.98 [95\% Cl 0.97 to 0.99]; $\mathrm{P}=0.004$ ) and three dimensions (HR 0.98 [95\% CI 0.97 to 0.99 ]; $\mathrm{P}=0.001)$ were significantly associated with lower mortality after TACE (Table 5).

Moreover, if patients experienced a reduction in the size of the tumour of $3 \%$ or more assessed in one, two or three dimensions, they had a lower risk of mortality (HR 0.48 [95\% CI 0.21 to 0.95]; $\mathrm{P}=0.04$; HR 0.36 [95\% CI 0.17 to 0.80]; P=0.01; and HR 0.31 [95\% CI 0.14 to $0.67]$; $\mathrm{P}=0.003$, respectively) (Table 5).

Conventional classifications (ie, WHO, RECIST and EASL) were not useful in predicting mortality after the first TACE when patients 


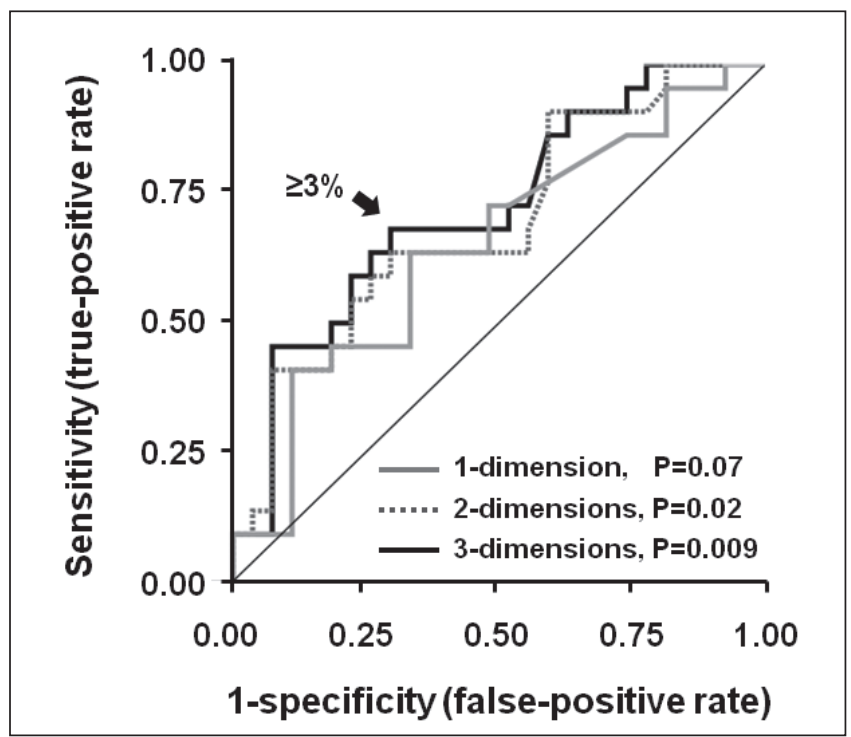

Figure 2) ROC curves for predicting mortality after transarterial chemoembolization in patients with hepatocellular carcinoma. The area under the curve (AUC) for two-dimensional tumour size reduction was 69 (95\% CI 0.54 to $0.84 ; P=0.02$ ), and for three-dimensional measurement, the AUC was 0.72 (95\% CI 0.58 to 0.86; $P=0.009$ ). The onedimensional measurement was less accurate for six-month mortality discrimination (AUC 0.65 [95\% CI 0.50 to 0.81]; P=0.07)

with partial response and stable disease were compared with patients with progressive disease, or when comparing patients with partial response to patients with stable and progressive disease (Table 5).

In the multivariate Cox analysis, only the response measured in three dimensions was independently associated with a reduction in mortality risk after TACE (HR 0.94 [95\% CI 0.89 to 0.99]; $\mathrm{P}=0.03$ ) (Table 5).

Overall survival after TACE according to WHO, RECIST and EASL criteria

Using the WHO classification, median survival in partial response and stable disease $(n=49)$ was $17 \pm 3$ months ( $95 \%$ CI 11 to 24$)$, and in progressive disease $(n=4)$ was $17 \pm 12$ months (95\% CI 1 to 39 ; $P=0.9$

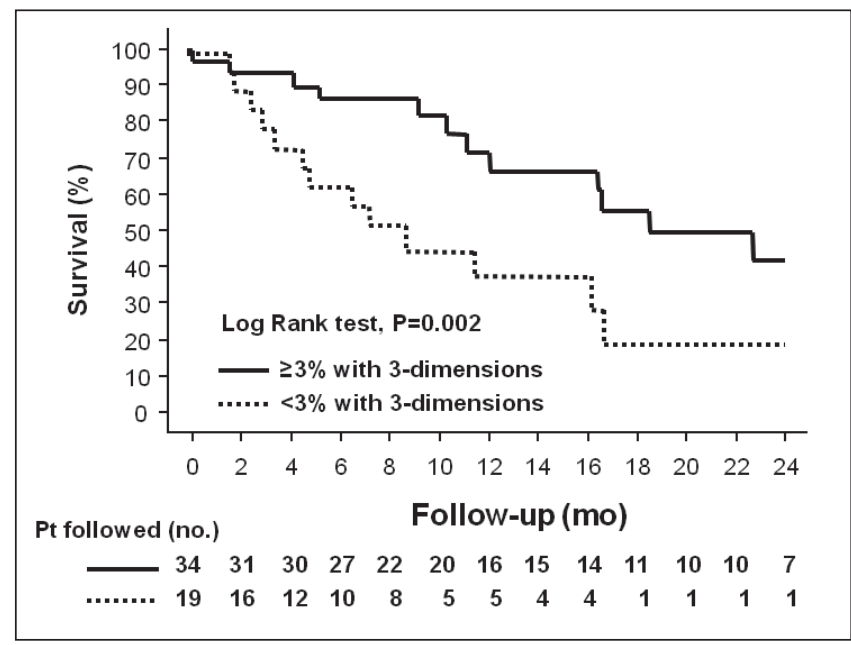

Figure 3) Kaplan-Meier survival curves of patients (Pt) with hepatocellular carcinoma after transarterial chemoembolization, separated into those who achieved a reduction in tumour size of $3 \%$ or more assessed in three dimensions compared with patients who did not ( $P=0.002$ [log-rank test). mo Months; no Number

[log-rank test]). Similar results were found using RECIST: partial response and stable disease $(n=51)$ was $17 \pm 3$ months (95\% CI 12 to 23$)$, and in progressive disease $(n=2)$ was $12 \pm 7$ months (95\% CI 1 to 26 ; $\mathrm{P}=0.9$ [log-rank test]); and EASL: partial response and stable disease ( $\mathrm{n}=51$ ) was $27 \pm 3$ months (95\% CI 12 to 23 months), and in progressive disease $(n=2)$ was $12 \pm 7$ months (95\% CI 1 to $26 ; \mathrm{P}=0.9$ [log-rank test]).

Overall survival after TACE according to more than a 3\% reduction in tumour size

Survival was significantly improved in patients who achieved a reduction in tumour size of $3 \%$ or more assessed in one, two and three dimensions, compared with patients who did not achieve this end point. This difference was greater if the tumour was assessed in three dimensions: median survival for patients who achieved a reduction in tumour size was $24 \pm 5$ months versus $8 \pm 3$ months $(\mathrm{P}=0.002$ [log-rank test]) (Figure 3).

\section{TABLE 5}

Post-transarterial chemoembolization (TACE) features associated with mortality according to Cox regression analysis in patients with hepatocellular carcinoma

\begin{tabular}{|c|c|c|c|c|c|}
\hline & Mortality $(n=28)$ & Alive $(n=25)$ & HR & $95 \% \mathrm{Cl}$ & $\mathbf{P}$ \\
\hline \multicolumn{6}{|c|}{ Features associated in the univariate analysis } \\
\hline WHO: PR + SD versus PD & $26: 2$ & $23: 2$ & 1.07 & $0.25-4.59$ & 0.9 \\
\hline RECIST: PR + SD versus PD & $27: 1$ & $24: 1$ & 0.94 & $0.13-7.04$ & 0.9 \\
\hline WHO: PR versus SD + PD & $4: 24$ & $4: 21$ & 1.36 & $0.47-3.94$ & 0.6 \\
\hline RECIST: PR versus SD + PD & $4: 24$ & $2: 23$ & 2.98 & $0.98-9.04$ & 0.06 \\
\hline EASL: PR versus SD + PD & $5: 23$ & $3: 22$ & 1.08 & $0.41-2.86$ & 0.9 \\
\hline Response with 2D, $\mathrm{cm}^{2}$ & $5.5 \pm 5.9$ & $28.5 \pm 6.8$ & 0.98 & $0.97-0.99$ & 0.004 \\
\hline Response with $3 \mathrm{D}, \mathrm{cm}^{3}$ & $4.6 \pm 8.3$ & $42 \pm 10$ & 0.98 & $0.97-0.99$ & 0.001 \\
\hline Reduction $>3 \%$ with $1 \mathrm{D}$ & $13(46)$ & $16(64)$ & 0.48 & $0.21-0.95$ & 0.04 \\
\hline Reduction $>3 \%$ with $2 \mathrm{D}$ & $14(50)$ & $17(68)$ & 0.36 & $0.17-0.80$ & 0.01 \\
\hline Reduction $>3 \%$ with $3 \mathrm{D}$ & $15(54)$ & $19(76)$ & 0.31 & $0.14-0.67$ & 0.003 \\
\hline \multicolumn{6}{|c|}{ Features associated in the multivariate analysis } \\
\hline
\end{tabular}

Data presented as $n: n$, mean \pm SEM or $n$ (\%). Percentage of response measured as difference in size between the pre-TACE computed tomography scan and the first computed tomography scan post-TACE, expressed as percentage. 1D One dimension; 2D Two dimensions; 3D Three dimensions; EASL European Association for the Study of the Liver criteria; PD Progressive disease; PR Partial response; RECIST Response Evaluation Criteria in Solid Tumors; SD Stable disease 


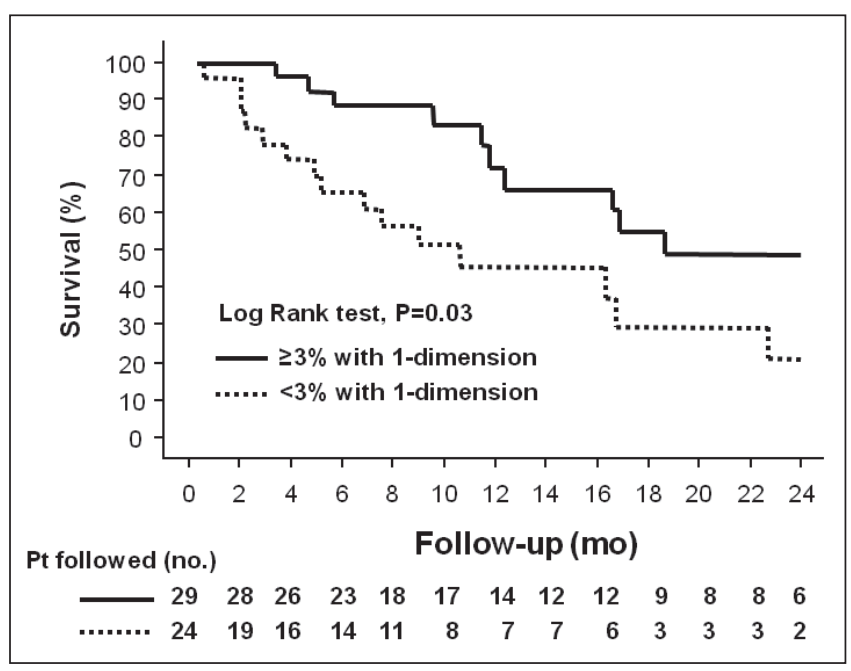

Figure 4) Kaplan-Meier survival curves of patients (Pt) with hepatocellular carcinoma after transarterial chemoembolization, separated into those who achieved a reduction in tumour size of 3\% or more assessed in one dimension and those who did not ( $P=0.03$ [log-rank test]). mo Months; no Number

Median survival in patients who achieved a reduction in tumour size of $3 \%$ or more assessed in one dimension was $19 \pm 7$ months versus $9 \pm 3$ months $(\mathrm{P}=0.03$ [Log-rank test]) (Figure 4). For patients who achieved a reduction in tumour size of $3 \%$ or more assessed in two dimensions, median survival was $24 \pm 5$ months versus $9 \pm 4$ months $(\mathrm{P}=0.009$ [log-rank test]) (Figure 5]).

\section{DISCUSSION}

Our study showed that the median survival after the first TACE in patients with HCC who were not eligible for curative treatments was approximately 17 months, which was similar to previous reports (17-24). Moreover, $5 \%$ of our patients died from treatment complications after the first TACE - a frequency similar to the findings of other investigators $(5,6)$.

We found that having an AFP level of greater than $200 \mathrm{ng} / \mathrm{mL}$ and a MELD score of greater than 10 were associated with two- and four-fold increases in the risk of mortality after TACE (Table 3). Moreover, reduction in tumour size assessed in one, two and three dimensions and, specifically a reduction of $3 \%$ or more, were associated with a one- to threefold reduction in the risk of mortality after TACE, while the response assessed in three-dimensions was the only independent factor associated with improved survival after TACE (Table 5).

Of note, we found that conventional classifications, such as WHO, RECIST and EASL, were not useful for predicting mortality in patients with advanced HCC. This could be because none of our patients achieved complete response, and the majority of our patients (approximately 80\%) were classified as having stable disease according to the three classifications (Table 4). Stable disease is a broad category because it includes patients with positive response with decreases in tumour size of up to $50 \%$ from baseline, and patients with negative response with increases in tumour size of up to $25 \%$ (Table 1).

The main end point for the evaluation of response to treatment in patients with HCC is overall survival; however, tumour response has been considered a good surrogate for efficacy. Originally, the WHO $(8,9)$ and RECIST $(10,11)$ criteria were developed for the evaluation of cytotoxic agents because these classifications assess antitumor activity according to the reduction in tumour size. Similar to our results, one study (25) showed a poor correlation between clinical improvement and response assessment with conventional classifications (WHO and RECIST) after TACE using drug-eluting beads or percutaneous ablation (percutaneous ethanol injection or radiofrequency ablation).

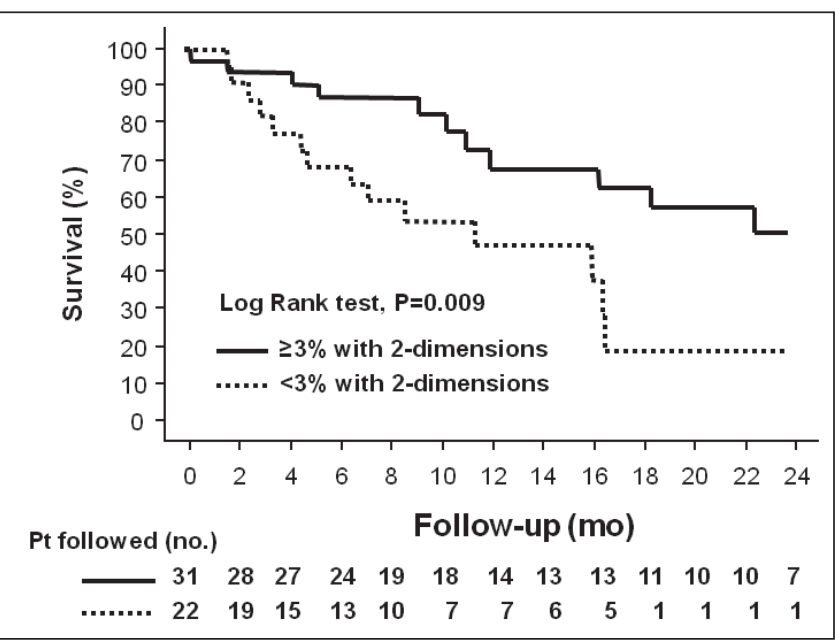

Figure 5) Kaplan-Meier survival curves of patients (Pt) with hepatocellular carcinoma after transarterial chemoembolization, separated into those who achieved a reduction in tumour size of 3\% or more assessed in two dimensions and those who did not $(P=0.009$ [log-rank test]). mo Months; no Number

In that study, the authors showed that conventional classifications missed all of the complete responses and underestimated the extent of partial tumour response because of tumour necrosis, wrongly assessing the therapeutic efficacy of locoregional therapies. Furthermore, the authors suggested that the evaluation should incorporate the reduction in viable tumour burden as recognized by nonenhancing areas on dynamic imaging studies, as included in the EASL criteria (12).

The EASL criteria may be able to detect more patients who achieved complete response compared with the WHO and RECIST criteria; however, the EASL criteria have not been shown to have better performance in discriminating improved survival. In fact, the performance of the three classifications in our study was similiar - none of our patients experienced complete response according to the EASL criteria and, again, most cases were classified as stable disease (Table 4).

Moreover, a recent study (26) has suggested the use of the modified RECIST to assess response in patients with HCC. These criteria are similar to RECIST, but also consider the disappearance or decrease of intratumoral arterial enhancement in the target lesion. However, additional studies are needed to confirm the accuracy of this measurement.

Recently, assessment of the total tumour volume was useful for candidate selection of patients with HCC, with post-transplant outcomes not different from those achieved with conventional classification, such as the Milan and the University of California, San Francisco (USA) criteria $(13,27)$. Therefore, we decided to determine whether there were differences in response assessment after TACE using one-, two- or threedimensional measurement. Interestingly, we found that assessment of response using three-dimensional measurement was more effective at predicting survival after TACE compared with one- and two-dimensional measurement, possibly because it provides a better estimate of the decrease in tumour size.

The fact that an AFP level of greater than $200 \mathrm{ng} / \mathrm{mL}$ was associated with increased risk of mortality is a novel but expected correlation. A recent study (28) showed that the use of AFP response (defined as more than a 50\% decrease from baseline) seen after locoregional therapy can be used as an ancillary method of assessing tumour response and survival, as well as an early objective screening tool for progression by imaging.

It is important to mention the limitations of the present study, such as its retrospective nature and the relatively small sample size $(n=60)$. Another limitation was the lack of data regarding interobserver variation in the assessment of tumour response to TACE because imaging studies were evaluated by only one radiologist (RO). Furthermore, because we used tridimensional measurement to evaluate response 
after TACE, we assumed HCC to be a spherical tumour, which in many cases, is not correct. Nevertheless, it seems that this assumption is more accurate than using one- and two-dimensional analysis in predicting survival, and more time efficient than computed tomography volumetry in assessing three-dimensional response. Finally, we only analyzed factors before and after the first TACE procedure, and most patients underwent more than one TACE (mean $2.5 \pm 0.2$, range 1 to 8 ). However, despite these limitations, we believe that our study should encourage future studies to evaluate more effective ways to assess tumour response after locoregional treatments in patients with HCC.

\section{SUMMARY}

Mean survival after TACE in patients with noncurative HCC was approximately 17 months. Having an AFP level of greater than $200 \mathrm{ng} / \mathrm{mL}$ and a MELD score of greater than 10 before TACE was associated with a greater risk of mortality. Conventional classifications of response, such as WHO, RECIST and EASL, are not useful for predicting mortality. Reduction in tumour size after the first TACE procedure was associated with improved survival, primarily if patients experienced a reduction of more than $3 \%$ in tumour size assessed using three-dimensional measurement.

DISCLOSURE: This study was presented, in part, at the Annual Meeting of the American College of Gastroenterology in San Diego, California, on October 26, 2009.

\section{REFERENCES}

1. Parkin DM, Bray F, Ferlay J, Pisani P. Estimating the world cancer burden: Globocan 2000. Int J Cancer 2001;94:153-6.

2. Mazzaferro V, Regalio E, Doci R, et al. Liver transplantation for the treatment of small hepatocellular carcinomas in patients with cirrhosis. N Engl J Med 1996;334:693-9.

3. Yao FY, Ferrell L, Bass NM, et al. Liver transplantation for hepatocellular carcinoma: Expansion of the tumor size limits does not adversely impact survival. Hepatology 2001;6:1394-403.

4. Llovet JM, Burroughs A, Bruix J. Hepatocellular carcinoma. Lancet 2003;362:1907-17.

5. Lo CM, Ngan H, Tso WK, et al. Randomized controlled trial of transarterial lipiodol chemoembolization for unresectable hepatocellular carcinoma. Hepatology 2002;35:1164-71.

6. Llovet JM, Real MI, Montana X, et al. Arterial embolisation or chemoembolisation versus symptomatic treatment in patients with unresectable hepatocellular carcinoma: A randomized controlled trial. Lancet 2002;359:1734-9.

7. Llovet JM, Bruix J. Systematic review of randomized trials for unresectable hepatocellular carcinoma: Chemoembolization improves survival. Hepatology 2003;37:429-42.

8. Miller AB, Hoogstraten B, Staquet M, Winkler A. Reporting results of cancer treatment. Cancer 1981;47:207-14.

9. World Health Organization. WHO Handbook for Reporting Results of Cancer Treatment. Offset Publication 48. Geneva: World Health Organization, 1979.

10. Therasse P, Arbuck SG, Eisenhauer EA, et al. New guidelines to evaluate the response to treatment in solid tumors. European Organization for Research and Treatment of Cancer, National
Cancer Institute of the United States, National Cancer Institute of Canada. J Natl Cancer Inst 2000;92:205-16.

11. Therasse P, Eisenhauer EA, Verweij J. RECIST revisited: A review of validation studies on tumour assessment. Eur J Cancer 2006;42:1031-9.

12. Bruix J, Sherman M, Llovet JM, et al. Clinical management of hepatocellular carcinoma. Conclusions of the Barcelona-2000 EASL conference. European Association for the Study of the Liver. J Hepatol 2001;35:421-30.

13. Toso C, Trotter J, Wei A, et al. Total tumor volume predicts risk of recurrence following liver transplantation in patients with hepatocellular carcinoma. Liver Transpl 2008;14:1107-15.

14. Heinze G, Gnant M, Schemper M. Exact log-rank tests for unequal follow-up. Biometrics 2003;59:1151-7.

15. Cox DR. Regression models and life tables (with discussion). JR Stat Soc B 1972;34:187-220.

16. Hanley JA, McNeil BJ. The meaning and use of the area under a receiver operating characteristic (ROC) curve. Radiology 1982;143:29-36.

17. Kasugai H, Kojima J, Tatsuta M, et al. Treatment of hepatocellular carcinoma by transcatheter arterial embolization combined with intraarterial infusion of a mixture of cisplatin and ethiodized oil. Gastroenterology 1989;97:965-71.

18. Chang JM, Tzeng WS, Pan HB, et al. Transcatheter arterial embolization with or without cisplatin treatment of hepatocellular carcinoma. A randomized controlled study. Cancer 1994;74:2449-53.

19. Bronowicki JP, Vetter D, Dumas F, et al. Transcatheter oily chemoembolization for hepatocellular carcinoma. A 4-year study of 127 French patients. Cancer 1994;74:16-24.

20. Stefanini GF, Amorati P, Biselli M, et al. Efficacy of transarterial targeted treatments on survival of patients with hepatocellular carcinoma. An Italian experience. Cancer 1995;75:2427-34.

21. Hatanaka Y, Yamashita Y, Takaha, et al. Unresectable hepatocellular carcinoma: Analysis of prognostic factors in transcatheter management. Radiology 1995;195:747-52.

22. Chung JM, Park JH, Han JK, et al. Hepatic tumors: Predisposing factors for complications of transcatheter oily chemoembolization. Radiology 1996;198:33-40.

23. Solomon B, Soulen MC, Baum RA, et al. Chemoembolization of hepatocellular carcinoma with cisplatin, doxorubicin, mitomycin-C, ethiodol, and polyvinyl alcohol: Prospective evaluation of response and survival in a US population. J Vasc Interv Radiol 1999;10:793-8

24. Takayasu K, Muramatsu Y, Maeda T, et al. Targeted transarterial oily chemoembolization for small foci of hepatocellular carcinoma using a unified helical CT and angiography system: Analysis of factors affecting local recurrence and survival rates. Am J Roentgenol 2001;176:681-8.

25. Forner A, Ayuso C, Varela M, et al. Evaluation of tumor response after locoregional therapies in hepatocellular carcinoma: Are response evaluation criteria in solid tumors reliable? Cancer 2009;115:616-23.

26. Lencioni R, Llovet JM. Modified RECIST (mRECIST) assessment for hepatocellular carcinoma. Semin Liver Dis 2010;30:52-60.

27. Toso C, Asthana S, Bigam DL, et al. Reassessing selection criteria prior to liver transplantation for hepatocellular carcinoma utilizing the Scientific Registry of Transplant Recipients database. Hepatology 2009;49:832-8.

28. Riaz A, Ryu RK, Kulik LM, et al. Alpha-fetoprotein response after locoregional therapy for hepatocellular carcinoma: Oncologic marker of radiologic response, progression, and survival. J Clin Oncol 2009;27:5734-42. 


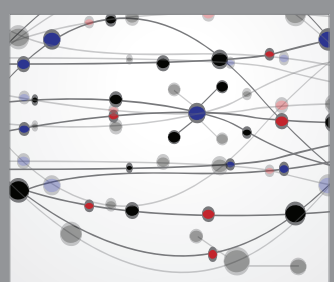

The Scientific World Journal
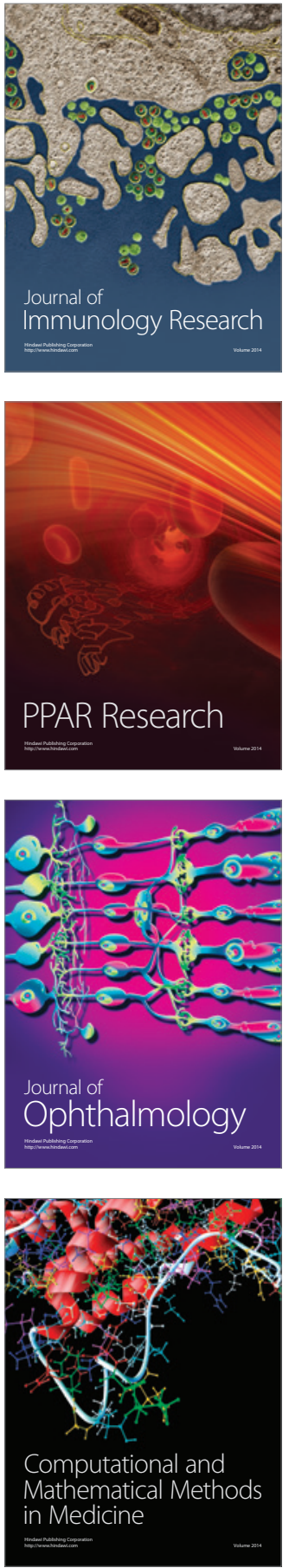

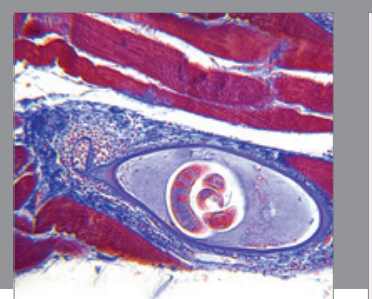

Gastroenterology Research and Practice

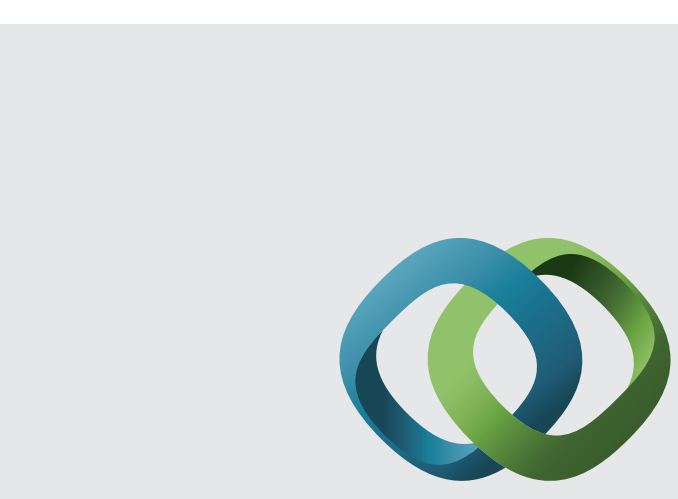

\section{Hindawi}

Submit your manuscripts at

http://www.hindawi.com
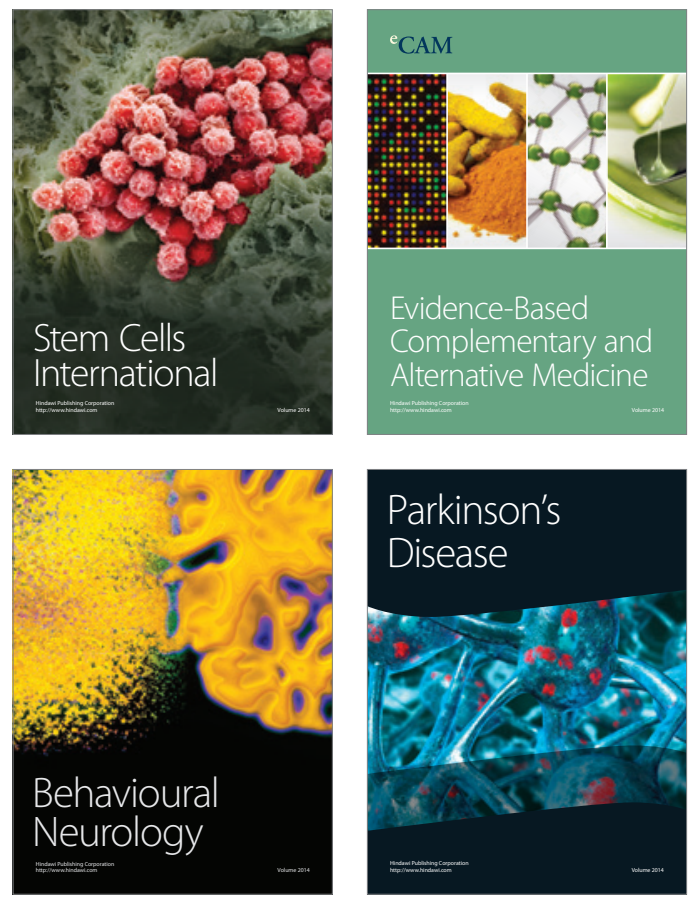
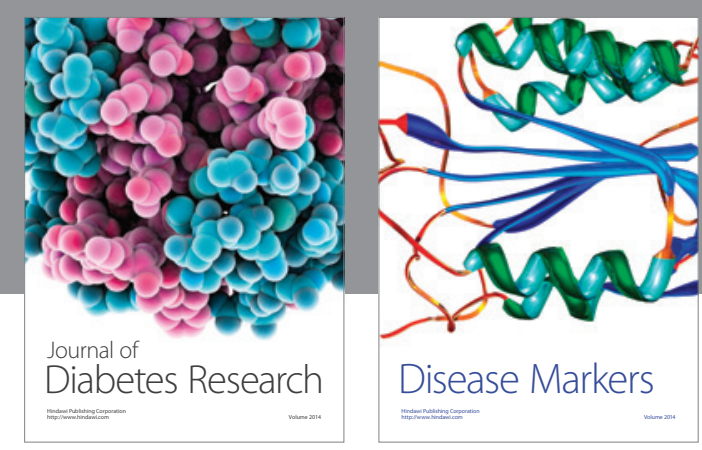

Disease Markers
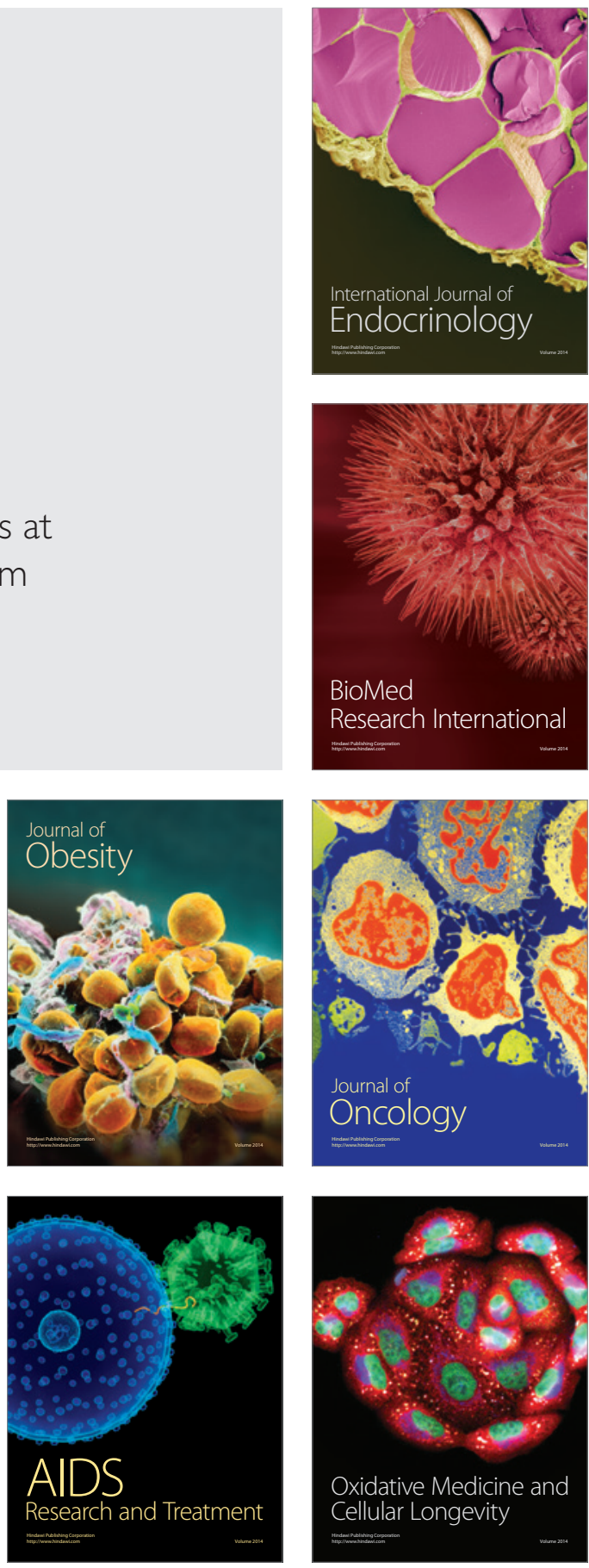